\title{
Ein Leben für die Seele
}

\section{Adrian Ritter}

Freier Journalist

\author{
Medizin und Psychiatrie setzen heute stark auf bildgebende Verfahren und Bio- \\ wissenschaften. Eine Publikation zu Ehren des Psychiaters Daniel Hell plädiert \\ dafür, daneben das seelische Erleben der Patienten nicht zu vernachlässigen.
}

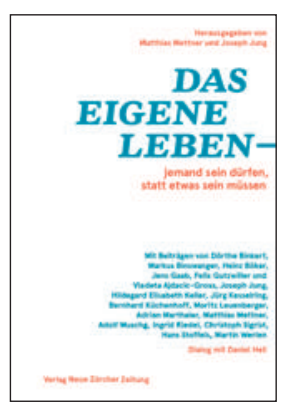

Matthias Mettner, Joseph Jung (Hrsg.) Das eigene Leben jemand sein dürfen, statt etwas sein müssen

Zürich: Verlag Neue Zürcher Zeitung; 2015. 214 Seiten. 34 CHF. ISBN 978-3-03810-101-7
Unermüdlich setzt sich der Mediziner, Psychiater und Psychotherapeut Daniel Hell seit Jahrzehnten für eine humane, am Menschen orientierte Psychiatrie ein. In den 1990er Jahren leitete er die Arbeitsgruppe, die ein neues Psychiatriekonzept für den Kanton Zürich erarbeitete. Dabei ging es ihm unter anderem darum, stationäre und ambulante Behandlung enger zu vernetzen. Neue Akzente setzte Daniel Hell von 1991 bis 2009 auch als ärztlicher und klinischer Direktor der Psychiatrischen Universitätsklinik Zürich (PUK). Zu den damaligen Reformen gehörte die Schaffung von neuen Behandlungsschwerpunkten für Suchtkranke, Frauen mit Kleinkindern und Migranten. Nach seiner Emeritierung leitete Daniel Hell bis 2014 das Kompetenzzentrum «Depression und Angst» an der Privatklinik Hohenegg in Meilen. Dort ist er jetzt als Stiftungsrat und in ambulanter Praxis tätig.

Mit der Publikation Das eigene Leben - jemand sein dürfen, statt etwas sein müssen legen Weggefährten von Daniel Hell eine Hommage vor an einen Mann, dessen Wirken weit über die Grenzen von Medizin, Psychiatrie und Psychotherapie hinausstrahlt, wie die Herausgeber schreiben. Mit ihren Beiträgen drücken rund 20 Autorinnen und Autoren ihre Dankbarkeit und Verbundenheit mit Daniel Hell aus. Die Idee zur Publikation geht auf ein Symposium zum 70. Geburtstag von Hell im Jahre 2014 zurück.

Ärzte und Psychiater wie Felix Gutzwiller, Vladeta Ajadcic-Gross und Markus Binswanger präsentieren im Buch den Erkenntnisstand der Suizidprävention

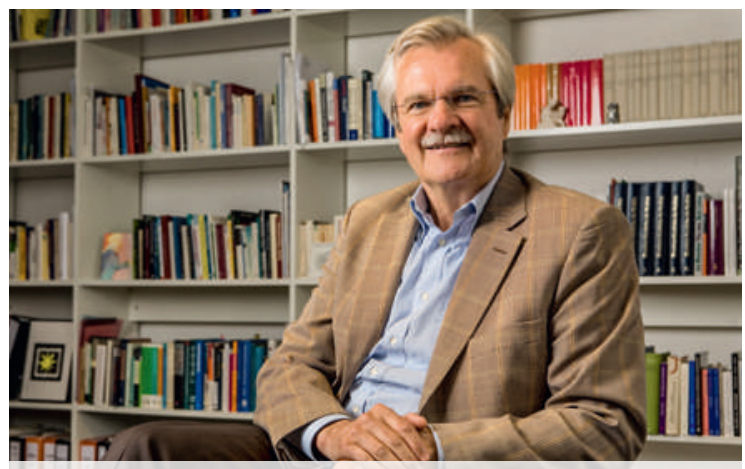

Das Buch ist auch eine Hommage an ihn: Daniel Hell. und die Wirksamkeit von Psychotherapie. Die Auswahl der Autoren und Themen widerspiegelt aber vor allem auch angrenzende Wissensbereiche, mit denen Daniel Hell die Psychiatrie verband - etwa die Theologie, Philosophie und Literatur.

So äussert sich Martin Werlen, der ehemalige Abt des Klosters Einsiedeln, zum Wert von Enttäuschungen für das menschliche Leben. Alt-Bundesrat Moritz Leuenberger sinniert darüber, wie Amt und Person sich in der Politik gegenseitig prägen und der Schriftsteller Adolf Muschg reflektiert über Schmerz und Tod. Abgerundet wird die Publikation durch ein Interview mit Daniel Hell und biographischen Informationen zu seiner Person.

\section{Psychiatrie mit Kopf und Herz}

Das Buch steht unter der Prämisse, dass die beschleunigte und pluralisierte Gegenwart es dem Menschen erschwert, ein stabiles Selbstwertgefühl zu entwickeln. Die fortwährende Identitäts- und Orientierungskrise zeige sich etwa in den Volkskrankheiten Depression und Angststörung.

Gemeinsam ist den Autorinnen und Autoren das Anliegen, in Zeiten bildgebender Hirnforschung, Gentechnologie und Biowissenschaften das seelische Erleben des Menschen nicht vergessen gehen zu lassen.

Auch Daniel Hell hatte neurowissenschaftliche Forschung betrieben. Gerade aus der Erfahrung ihrer methodischen Grenzen betont er aber in seinem Beitrag in der Publikation, dass die Befunde der Hirnforschung nicht mit dem ganzheitlichen Erleben des Menschen gleichzusetzen seien. Das Erleben von psychisch Kranken werde zunehmend wie ein Computerausdruck verdinglicht - «aus Jemand wird Etwas».

Hell verteidigte dagegen die Innensicht der Patienten gerade in der Psychiatrie als «Seelenheilkunde». Dabei ist für ihn klar, dass es die positive Beziehung zwischen Patient und Therapeut ist, die in der Behandlung das wirksamste Element darstellt. Er plädiert darum für die Ergänzung von Hightech um «Hightouch» - also therapeutische Zuwendung. Dabei gehe es weniger darum, über etwas zu reden als mit jemandem zu sprechen. 